DOI 10.37882/2500-3682.2021.11.05

\title{
СОВРЕМЕННАЯ ХУДОЖЕСТВЕННАЯ РОССИЯ В ИЗМЕРЕНИИ ИМАГОЛОГИИ
}

\section{MODERN ART RUSSIA \\ IN THE MEASUREMENT OF IMAGOLOGY \\ P. Kravchenko}

Summary: Russia is a culturally prestigious country, whose creative figures - writers, musicians and artists - have made and continue to make their contribution to world civilization throughout the history of the state.

Rapid globalization and regional cooperation between national cultures bring the Other's scientific research to life. These studies tend to perceive and interpret the different cultural processes of the partner countries. In the context of imagology, an interdisciplinary approach in the humanities is implemented, which studies persistent stereotypes about "other" nations, cultures and countries from the point of view of another nation or culture.

Keywords: Russia, culture, art, ethnos, imagology, cross-border, cultural program, cooperation, government.
$\mathrm{O}$ дним из основных направлений стратегии России в области культуры во внешних отношениях является охват этнических русских за рубежом, испытывающих ностальгические чувства по своей стране происхождения. В настоящее время правительство работает над разработкой новой стратегии. Эта стратегия строится вокруг следующих шести основных тем и задач:

- формирование имиджа России как «великой и известной» страны;

- работа с русской диаспорой;

- распространение русского языка;

- международный академический и студенческий обмен;

- сохранение культурного наследия;

- схема двусторонних отношений с зарубежными странами.

В рамках стратегии планируется систематическая организация различных мероприятий для популяризации исторических достижений России. В последние годы Министерство иностранных дел укрепило свою культурную инфраструктуру за рубежом. Оно отвечает за Россотрудничество, федеральное агентство, созданное для поддержания влияния России в Содружестве Независимых Государств (СНГ).

Российское правительство активно популяризует культуру, в особенности русских художников, музыкан-
Кравченко Петр Николаевич

Аспирант, Российская академия народного хозяйства и государственной службы при Президенте Российской Федерации (2. Москва) petroru@mail.ru

Аннотация: Россия - это престижная в культурном отношении страна, творческие деятели которой - писатели, музыканты и художники - вносили и продолжают вносить свой вклад в мировую цивилизацию на протяжении всей истории государства.

Быстрая глобализация и региональное сотрудничество между национальными культурами воплощают в жизнь научные исследования «Другого». Эти исследования имеют тенденцию познавать и интерпретировать различные культурные процессы стран-партнеров. В контексте имагологии реализуется междисциплинарный подход в гуманитарных науках, который изучает устойчивые стереотипы 0 «других» нациях, культурах и странах с точки зрения другой нации или культуры.

Ключевые слова: Россия, культура, искусство, этнос, культурная программа, сотрудничество, правительство.

тов, актеров для улучшения имиджа государства в мире. Тогда как в советский период культура использовалась главным образом как инструмент правительства для сохранения целостности коммунистической системы. Сегодня многие ведущие артисты России выступают и живут в разных странах мира, укрепляя имидж русской культуры за рубежом.

Крупные российские компании, такие как Газпром, различные российские олигархи, а также международные корпорации, такие как Группа Ротшильдов, входящая в их попечительские советы, вносит свой вклад в социальные программы крупнейших культурных учреждений России. В настоящее время правительство работает над новой стратегией развития культуры во внешних связях, однако эти изменения в силу пандемии во всем мире идут слишком медленно.

Одним из основных направлений стратегии России в области культуры во внешних отношениях является охват этнических русских за рубежом, испытывающих ностальгические чувства по своей стране происхождения. Еще 12 декабря 2012 года президент В.В. Путин объявил Федеральному Собранию России, что правительство намерено продвигать русскую культуру и язык в своих международных отношениях, увеличивать студенческий обмен. 
Таким образом, правительство России желает улучшить имидж страны во всем мире. Культурное наследие России используется как ключевой компонент построения этого имиджа, как маркер российской национальной идентичности и как источник гордости. «Согласно Федеральной целевой программе, именно культура является духовно-нравственной основой страны» [9, с. 139]. Средства массовой информации и Православная церковь - инструменты, которые не менее активно используются государством для реализации своей стратегии развития культуры.

Развитие отношений с русской диаспорой - ключевой элемент российской стратегии. Он осуществляется через организацию недель российского кино, театральных представлений, концертов, выставок, литературных дебатов. Культурные взаимодействия сосредоточены на распространении русского языка, особенно в бывших советских республиках, где проживают большие русскоязычные меньшинства. Русский - один из самых распространенных языков в мире, но его использование сокращается.

СНГ и Китай - приоритетные страны для России. В этих странах есть большие русские общины, и именно по этой причине они остаются важными для России. Между ними существует огромный потенциал для расширения культурного сотрудничества и дальнейшего продвижения русской культуры на международном уровне.

Схема двусторонних «Годов культуры» - за последние несколько лет Россия организовала двусторонние «Годы» со следующими странами-членами ЕС: Франция (2010 г.), Италия (2011 г.), Германия (2012 г.), Нидерланды (2013 г.) и Австрия. (2013-14). 2014 год - год Великобритании и России. По мнению Британского Совета, этот двусторонний год стал важным шагом на пути к выстраиванию стратегического сотрудничества между Британским Советом и Министерством иностранных дел России. Кроме того, уровень культурной активности повысился в обеих странах во всех секторах.

Туризм также является частью стратегии России в отношении культуры во внешних отношениях. В Новой Государственной программе на 2013-2020 годы упоминается, что «правительство намерено использовать туристический сектор как инструмент для сохранения и популяризации культурного и исторического наследия России» [1]. Для достижения этой цели он планирует принять меры по раскрытию потенциала своего культурного и творческого сектора и повысить качество и доступность своих туристических услуг для иностранных туристов.

По сравнению со странами-членами ЕС в Российской Федерации мало инструментов и институтов для про- движения культуры во внешних отношениях, но Россия увеличивает количество центров и бюджет своих агентств, занимающихся продвижением русской культуры и языка за рубежом. Основная ответственность лежит на Министерстве иностранных дел, которое является контактным лицом для российских учреждений и их партнерских организаций за рубежом.

Министерство культуры занимается сохранением культурного наследия и продвижением российского кино. Федеральное агентство по туризму и архивам связано с Министерством культуры и поддерживает международные проекты и учреждения культуры за рубежом. У Министерства культуры есть официальный портал, на котором представлена информация о российской культуре, истории, текущих событиях, а также обзор основных международных партнеров.

Важную роль играет также Министерство связи и массовых коммуникаций Российской Федерации. Они несут ответственность за регулирование средств массовой информации, таких как радио, телевидение, Интернет и издательское дело, а также за связь и международные отношения.

Министерство образования и науки отвечает за международное сотрудничество в области науки и образования. Оно регулярно присуждает стипендии иностранным студентам для обучения в России и изучения русского языка.

Россотрудничество - Федеральное агентство по делам Содружества Независимых Государств, соотечественников, проживающих за рубежом, и по международному гуманитарному сотрудничеству. Агентство было создано бывшим президентом России Дмитрием Медведевым в 2008 году «для поддержания влияния России в СНГ и развития дружеских связей для продвижения политических и экономических интересов России в зарубежных странах» [8]. Агентство находится в Москве, а Министерство иностранных дел развивает сеть российских научных и культурных центров за рубежом. Сейчас существует 70 центров, а в 2012 году был открыт новый офис в Лондоне.

Президент В.В. Путин поддерживает преподавание русского языка в СНГ, воздействует на удовлетворение культурных и языковых потребностей соотечественников, проживающих за рубежом, и предоставляет учебные материалы примерно в 7000 школ по всему миру, где преподается русский язык. По данным Министерства образования, количество школ, в которых преподается русский язык, увеличивается, и правительство желает отправлять больше русских учителей за границу.

Фонд «Русский мир» - это благотворительный фонд, 
созданный совместно Министерством иностранных дел и Министерством образования и науки. Он поддерживается как государственными, так и частными фондами. Был основан в 2007 году президентом В.В. Путиным для популяризации русского языка и культуры во всем мире как важнейшего элемента мировой цивилизации.

«Фонд развивает российские центры в партнерстве с образовательными организациями (в основном университетами) по всему миру. Эти центры поддерживают программы изучения русского языка, имеют библиотеки и управляются людьми разных национальностей» $[5$, с. 146]. Они также развивают связи с российскими университетами, стараются привлечь иностранных студентов для обучения в России и организовывают образовательные выставки.

В Китае, например, они посещают выставки, чтобы продвигать российские университеты в различных городах Китая. Более 10000 иностранных студентов приезжают в Россию на учебу, и для них создана специальная сеть / платформа для выпускников. Правительство стремится улучшить мировой рейтинг университетов страны.

В России продвижением русской культуры и языка занимаются также следующие органы:

- Институт Пушкина, ответственный за распространение информации о преподавании русского языка. Сертификат Пушкина соответствует стандартам Общеевропейских компетенций владения иностранным языком (CEFR);

- Госфильмофонд - Национальный кинофонд России, который поддерживает российские фильмы и международное продвижение российских фильмов через организацию кинофестивалей;

- Российская академия художеств (РАХ), некоммерческое учреждение, занимающееся развитием искусства в России. Поддерживает выставки русских художников за рубежом, а также выставки зарубежных художников в России;

- Российский совет академической мобильности (Росам), некоммерческая организация, содействующая международному обмену студентами и учеными.

В России существует семь федеральных округов, в которых вместе функционируют 83 административно-территориальных единицы, занимающихся культурными проектами. «Эти региональные администрации входят в состав Координационного совета по культуре Министерства культуры и имеют полномочия взаимодействовать с иностранными властями» [6, с. 130]. Они играют важную роль, поскольку Россия - этнически разнообразная страна.
Региональные и местные власти в России могут взаимодействовать с иностранными властями, «но их открытость для других стран во многом зависит от губернатора федерального округа» [10, с. 68]. Например, министр культуры Перми начал кампанию по «открытию» программы «Культурная столица Европы» для стран, не входящих в ЕС. Несмотря на то, что города страны не имеют права на участие в программе, он подал заявку на то, чтобы город Пермь стал культурной столицей Европы после 2020 года, и несколько раз посетил Брюссель, чтобы защитить свое предложение. Когда он переехал в Москву и начал работать в Министерстве культуры России, новый губернатор, менее «европейски настроенный», отозвал заявление своего предшественника.

Не так давно Россия подписала соглашения о сотрудничестве с Бразилией. Хорошим примером проекта российской культурной дипломатии в Бразилии является Школа Большого театра в Бразилии. Это единственная школа знаменитого Большого театра за пределами Москвы, которая предоставляет стипендии, включая питание, форму, транспорт, медицинскую помощь и физиотерапию для малообеспеченных детей из семей города Жоинвиль в южном штате Санта-Катарина.

В последние годы отношения между Россией и Китаем быстро развиваются и углубляются. В связи с последними событиями политического и культурного характера роль России и Китая на мировой арене усиливается, В течение особенно 2010-2020 годов этот процесс шёл чрезвычайно быстрыми темпами, оказывая огромное влияние на международную обстановку.

Однако не только внешние ситуативные обстоятельства влияют на сближение России и Китая. Сближение двух стран - это естественный процесс, обусловленный, прежде всего, внутренними причинами, поскольку наши страны - это давние соседи, они имеют большую общую границу и большие общие интересы. Из этого факта логически вытекают и усиление среди китайского населения интереса к русскому языку.

Актуальность изучения и качественного преподавания русского языка возрастает с каждым днем. Язык это средство коммуникации, очень важное для культурного обмена между двумя странами. Без него нам трудно связываться. Конечно, «проблема межкультурной коммуникации на любом языке не сводится исключительно к языковой проблеме. Знание языка носителя иной культуры необходимо, но еще недостаточно для адекватного взаимопонимания участников коммуникативного акта» $[7$, c. 68].

Как показала практика, даже глубокого знания иностранного языка недостаточно для эффективного общения с его носителем: каждое слово другого языка от- 
ражает другой мир и другую культуру. Главная задача в изучении иностранных языков как средства коммуникации заключается в том, что языки должны изучаться в неразрывном единстве с миром и культурой народов, говорящих на этих языках.

Поэтому в целях развития дружбы и культурных обменов между двумя странами изучение русского языка, даже русской культуры стало незаменимой дисциплиной для нашей страны в Китае. А как русский язык и русская культура развивают и как они становятся основными дисциплинами в восприятии в Китае, являются следующим исследовательским фокусом автора.

Ученые выделят несколько форм межкультурной коммуникации. Например, «аккультурация как форма межкультурной коммуникации. Культурные контакты являются важным компонентом общения между народами. Аккультурация представляет одновременно процесс и результат взаимного влияния разных культур, при котором все или часть представителей одной культуры (культуры-реципиента) перенимают нормы, ценности и традиции другой (культуры-донора)» [2, с. 93]. Фактически понятие аккультурации синонимично понятию межкультурной коммуникации, «его содержание отражает различные формы коммуникации культур» [3, с. 578].

Музыкальная культура является органической частью культуры народа, к которому принадлежит каждый человек, или среди которого он живет. Без музыки, в том числе и песенного фольклора, трудно убедить индивида, который изучает этот мир, в том, что человек прекрасен. А это убеждение, по сути, является основой эмоциональной, эстетической, нравственной культуры этноса [4].

Считается, что знание русского песенного фольклора какого-то народа является знакомством с этим народом, так как именно через песенный фольклор открывается сама сфера духовности каждого этноса. С позиции музыки, роль русского песенного фольклора в мировой культуре неоценима, ведь простая народная музыка, подобранная и филигранно заточена на народный вкус, в сочетании с текстом воплощают отношение народа к действительности.
Народная песня не существует без мелодии, вызывает слуховые впечатления и образы у самих участников выполнения произведения и у его пассивных слушателей. Неоднократное повторение любимых фольклорных песен укрепляло индивидуальные и коллективные традиции прадедов. Через песню передавались те чувства и переживания, которые невозможно и недостаточно было просто выразить словами. Характерная мелодия создавала соответствующее настроение и атмосферу. Такая песня способна окрылять, повышать настроение, вдохновлять на смелые, а порой и отчаянные поступки.

Китайское население отлично понимает, что фольклорная песня, как результат духовного труда этноса многих веков, является чрезвычайно ценным культурным достоянием русского народа. Она пропитана гуманными и свободолюбивыми идеями, развивает и преподносит все, что есть хорошего и доброго в человеческой душе, питает чувство красоты, поддерживает национальное сознание и историческую традицию. Едва ли не сама роль песни - это бороться с проблемой угасания следов духовной деятельности человека с течением времени.

Китайцы также поддерживают мнение, что русская фольклорная песня - это четкий фактор региональной принадлежности. Определенный процент стилистически маркированной лексики в песне выдает ее корни; диалектизмы, просторечия совсем не портят впечатление от песни, а наоборот, добавляют особенный шарм. Изучение диалектов на базе песенного фольклора дает информацию об устойчивых выражениях, фонетическом различии и тому подобное.

Подводя итоги исследования, отметим, что изучение вопросов развития современной художественной России в контексте имагологии является актуальным. Анализ специфики популяризации и укрепления русской культуры и искусства доказывает тот факт, что правительством страны разработано достаточно различных программ и концепций, которые позволяют изучать лучшие традиции русской культуры, как в масштабах государства, так и за рубежом.

\section{ЛИТЕРАТУРА}

1. Указ Президента Российской Федерации от 12 мая 2009 г. N 537 «0 Стратегии национальной безопасности Российской Федерации до 2020 года» [Электронный ресурс]. - Режим доступа: https://rg.ru/2009/05/19/strategia-dok.html (дата обращения - 19 октября 2021 года)

2. Будаева 3.А. Аккультурация как доминирующий теоретический маркер проявления процессов глобализации // Вестник Бурятского государственного университета. - 2014. - № 6-2. - С. 91-95.

3. Василик М.А. Основы теории коммуникации. М.: Гардарики, 2003. - 615 с.

4. Министерство образования Китайской Народной Республики [Электронный ресурс]. - Режим доступа: http://nic.gov.ru/ru/inworld/countries/China (дата обращения - 15 октября 2021 года)

5. Соколов М.С., Борисов А.В. - «Русский мир» как глобальный проект // Национальная безопасность / nota bene. - 2017. - № 3. - С. 143 - 150. 
6. Тлостанова М.В. Транскультурация как модель социокультурной динамики и проблема множественной идентификации // Вопросы социальной теории. 2011. - Т. 5. - С. 126-149.

7. Ушанова И.А. Перспективы развития теории аккультурации в глобализованном мире // Вестник Новгородского университета. - 2003. - № 24. - С. 65-70.

8. Федеральное агентство по делам Содружества Независимых Государств, соотечественников, проживающих за рубежом, и по международному гуманитарному сотрудничеству (Россотрудничество) [Электронный ресурс]. - Режим доступа: http://publication.pravo.gov.ru/SignatoryAuthority/foiv035 (дата обращения - 15 октября 2021 года)

9. Федорец М.Н. Федеральные округа: значимость и роль в государственно-территориальном устройстве Российской Федерации // Государство и право: журнал. - М.: Наука, 2018. - Октябрь (№ 10). - С. 139.

10. Черкасов К.В. Федеральные округа: сущность и место в территориальном устройстве России // Государство и право: журнал. - М.: Наука, 2008. - Декабрь (№ 12). - C. 68.

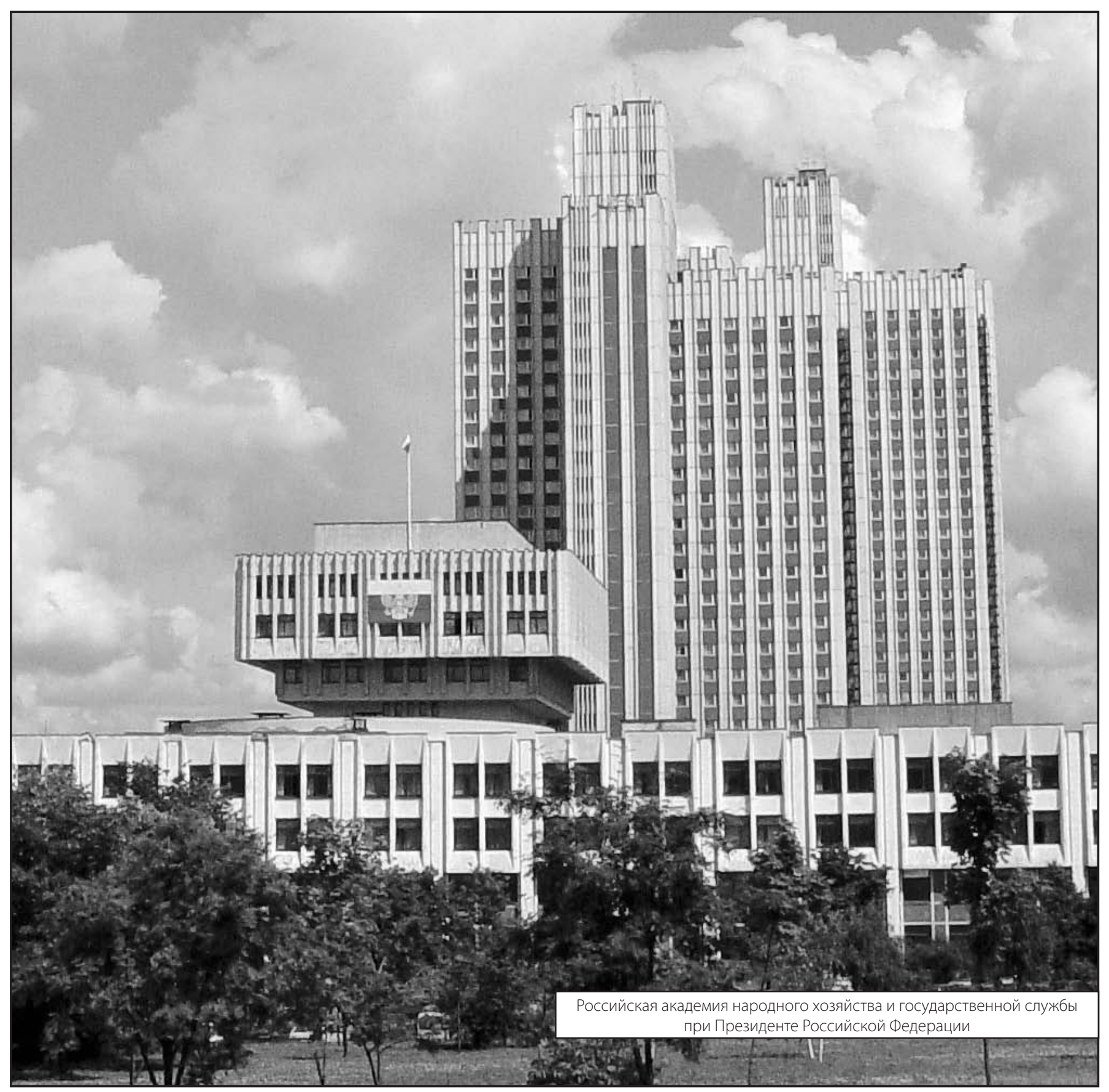

